\title{
A Study on the Influencing Factors of Mobile Digital Music Selection in Subhealthy People Based on Perceived Value Theory
}

\author{
Ming Jiang $₫$, ${ }^{1}$ Liming Lin, ${ }^{1}$ Weiguo Zhang, ${ }^{1}$ Weiqing Zhuang, ${ }^{1}$ Minghui Jin, ${ }^{1}$ and Yi Lin ${ }^{2}$ \\ ${ }^{1}$ Fujian University of Technology, Fuzhou 350118, China \\ ${ }^{2}$ Fujian Normal University, Fuzhou 350117, China
}

Correspondence should be addressed to Ming Jiang; 19842158@fjut.edu.cn

Received 28 January 2021; Revised 24 February 2021; Accepted 18 March 2021; Published 30 March 2021

Academic Editor: Chi-Hua Chen

Copyright (c) 2021 Ming Jiang et al. This is an open access article distributed under the Creative Commons Attribution License, which permits unrestricted use, distribution, and reproduction in any medium, provided the original work is properly cited.

\begin{abstract}
Background. The mode of combining mobile terminals and mobile digital music has gradually entered a bottleneck period while promoting the development of the mobile terminal industry. Proposing personalized solutions for specific groups of people including subhealthy people has become the current direction for the further long-term development of this mode. Understanding the influencing factors that affect subhealthy people's selection of mobile digital music is an urgent problem that needs to be solved in the development of personalized solutions. Objective. This article analyzes the influencing factors of the purchase intent to buy mobile digital music for subhealthy people and provides suggestions for mobile terminal vendors on how to design personalized solutions for this group of people. Methods. In order to achieve the above goals, this article constructs an influencing factor model based on the theory of perceived value, collects data by means of questionnaires, and uses the method of structural equations to verify the proposed model. Results. The results show that perceived quality, perceived price, social value, and emotional value all have a significant effect on users' purchase intention. Meanwhile, the conditional value and epistemic value have a negative moderating effect on the relationship between the social value and subhealthy people's digital music purchase intention but strengthen the positive relationship between the emotional value and subhealthy people's digital music purchase intention. Conclusions. The analysis shows that mobile terminal vendors should have their own unique attitudes and feelings when designing personalized mobile digital music solutions for subhealthy people, clarify their position, find strategies to improve the experience of subhealthy people, and win the reputation of subhealthy people. Let subhealthy people have a sense of belongingness.
\end{abstract}

\section{Introduction}

Since the advent of the first Walkman in the late 1970s, mobile music terminals have become an indispensable product in people's lives, especially, after Apple Inc. launched the iPod and iTunes store, a combination of mobile terminals and mobile digital music. The market has undergone a classic transformation of creative destruction, but with the advent of the digital age, this model is gradually facing development bottlenecks, and the personalized crowd customization model has increasingly become the mainstream of current development. Subhealthy people account for $85 \%$ of the global population, and music therapy is widely regarded as the most acceptable and effective method for this group of people. It is a matter of course that it has become a custom- ized group of personalized solutions that is widely concerned by mobile terminal vendors. The analysis of the influencing factors affecting the purchase intention of mobile digital music for this group of people is not only conducive to enriching the theoretical research in the field of information system management but also conducive to mobile terminal vendors to formulate appropriate personalized customized solutions on this basis.

The Yi Guan Research Center defines mobile digital music as the general term for users to obtain music and musicrelated services by using SMS and other access methods through mobile terminal devices like smartphones. At present, although scholars have carried out research on consumers' mobile digital music purchase intentions from the perspectives of consumer characteristics, personal personality 
characteristics, network-related factors, and cultural-related factors, the overall theoretical results are still scarce, especially for subhealthy people. Research on specific populations is still limited. Mobile terminal vendors also need more reference materials to continuously inspire diversified and innovative thinking, so that the industry can develop more prosperously.

Perceived value theory was first proposed by Zeithaml, and it is widely used in related research on perceived value and purchase intention. A large number of studies have shown that perceived value can better predict consumer purchase intentions than satisfaction or quality. Perceived value is defined here as the overall subjective evaluation of the utility of mobile digital music after weighing the benefits that the subhealthy people can perceive and the cost it pays for it.

We build on these studies by developing and testing a model that proposes how the different dimensions of perceived value interact to influence subhealthy people's digital music purchase intention. Specifically, we first examine the effects of four dimensions of perceived value (i.e., perceived price, perceived quality, social value, and emotional value) on subhealthy people's digital music purchase intention; then, we evaluate the moderating effects of conditional value and epistemic value on the relationship between above four perceived value dimensions and subhealthy people's digital music purchase intention.

We test our model using primary data collected from subhealthy people in four Chinese hospitals. Empirical results show that the perceived quality, emotional value, and social value have positive effects on subhealthy people's digital music purchase intention. Meanwhile, perceived price is negatively related to subhealthy people's digital music purchase intention. Furthermore, both relationships between four perceived value dimensions and subhealthy people's digital music purchase intention were moderated by the conditional value and epistemic value.

Our research extends extant literature about perceived value and mobile digital music selection by systematically examining the main effects and the interaction effects of different dimensions of perceived value on subhealthy people's digital music purchase intention. Firstly, we apply perceived value theory to the adoption of digital music, and this extends the scope of perceived value theory. Secondly, we complement the perceived value theory by testing the interaction effects of different dimensions of perceived value on subhealthy people's digital music purchase intention.

This article is divided into four parts. The first part is a review of related research domestically and internationally. The second part proposes the basic assumptions and influencing factor models of the research. The third part uses the structural equation method to verify the proposed model. Based on the empirical results, the fourth part provides specific suggestions for mobile terminal vendors to develop personalized solutions for subhealthy people.

\section{Related Work}

Mobile digital music technology and mobile terminal technology have changed the production, storage, and dissemina- tion of the music industry value chain, giving birth to a variety of business models. As the music content is no longer monopolized by the record company, a search engine, music studio, original individuals, music websites, and so on may become a music provider. Digital music, digital albums, online concerts, and other music products enrich the industry day by day. Currently, consumers, including subhealthy people, have access to mobile digital music by three ways: free ad, mobile terminal store, and pay per single songs or albums.

\subsection{Literature Review on Consumer Behavior of Digital} Music. With mobile wireless music as an example, Souza and Baldanza confirmed the moderating role of customer experience on customer perception and purchase intention, and the results show that the wireless music experience can significantly enhance the positive impact of perceived usefulness and perceived ease of use on perceived value and attitudes of use and the positive impact among perceived value, the attitudes of use, and purchase intention [1].

Lin et al. studied the downloading behavior of digital music in Taiwanese college students and found that awareness of digital music copyright would positively affect the paid download behavior but had no significant effect on perceived usefulness; perceived ease of use had positive effects on perceived usefulness and downloading behavior; perceived usefulness positively affected use intention [2].

Kim et al. based on the "perceived value-intention" model studied the purchase intention of online consumers in Taiwan and found that perceived value had a significant effect on purchase intention for online music, and the effect of perceived usefulness and perceived entertainment was more than that of perceived price [3].

Shaw and Sergueeva added the advantages of virtual products, inferior variables (convenience and perceived risk), and digital music characteristics (price, diversity, audition, and entertainment) into the rational behavioral model and held the ground that subjective norms, perceived risk, diversity, price, and perceived entertainment significantly affect consumer buying behavior [4].

In summary, scholars have conducted a preliminary exploration of the behavior of digital music consumers, and the main research content is divided into two aspects: influencing factors on the purchase intention of consumers from the physical music products to virtual digital music products and the factors driving consumers from free music to paid music in the case of the prevalence of pirated music. In respect of theory, the majority of studies have used the theory of consumer behavior as a research foundation.

In order to find out the driving factors that subhealthy people choose to purchase mobile digital music from mobile terminal and the influencing factor from free to payment, the research mainly takes the difference between mobile digital music and digital music for modeling.

2.2. Relevant Study on Perceived Value Theory. According to the "value-intention" model, perceived value is a stable component to predict consumers' purchase intention. A large number of empirical results also show that the more 
TABLE 1: Definition of Operability of each dimension variable of the perceived value.

\begin{tabular}{|c|c|}
\hline Variable & Definition \\
\hline Perceived price & The perceived price of money to digital music \\
\hline Social value & $\begin{array}{c}\text { The extent to which consumers believe that their purchase of digital music can improve self-concept and get the } \\
\text { certainty of others }\end{array}$ \\
\hline Emotional value & The extent to which consumers believe that the consumption of digital music pleases them and makes them positive \\
\hline Perceived quality & The extent to which the quality of product or service is perceived by the consumer \\
\hline Conditional value & The extent to which consumers believe that in the time and space conditions, digital music can convey the value \\
\hline Epistemic value & $\begin{array}{c}\text { The extent to which consumers believe that they can experience the sense of innovation or knowledge from } \\
\text { the consumption }\end{array}$ \\
\hline
\end{tabular}

consumers perceive the benefits of goods, the stronger their purchase intention [5-7].

With regard to the notion of perceived value, Itani et al. firstly portrayed the perceived value as a trade-off between consumer perception of perceived quality (intrinsic and extrinsic) and perceived price (money, time, energy, and search) from the perspective of economics [8]. Then, Sheth et al., Woodruff et al., and Holbrook et al. believed that the customer value can be divided into a product attribute layer, result layer, and target layer from the marketing, psychology, and social psychology, as the value judgment of consumers interacts in a specific context based on individual preferences. So the formation of perceived value not only is attributed to product or service but also is affected by emotional factors and situational factors [9]. Therefore, the measurement of perceived value needs to be carried out from multiple dimensions [10]. In addition to the functionality, material, and economics, objective rationality also includes the symbol, pleasure, and aesthetic and other emotional content [11].

Based on the above research on the concept of perceived value, Sweeney and Soutar developed a perceived value measurement scale [12] which includes 19 measures. On this basis, Pura developed a perceptual value model for studying mobile services by adding conditional value (time sufficiency, location proximity, equipment conditions, etc.) and epistemic value (curiosity and novelty) [13-15].

Based on the theory of consumers' perceived value, this paper divides the perceived value into profits and losses and then divides the two dimensions into external factors and related contents.

At present, there are few researches applying perceived value theory to study the driving factors of digital content (digital music, digital video, and digital news) on consumption intention. Therefore, this paper uses perceptual value as an independent variable to study the influencing factors of mobile digital music on subhealthy people's purchase intention. In the current market environment, exploring the driving factor of subhealthy people buying mobile digital music is the exploration of the application of perceived value theory in new fields.

\section{Conceptual Model and Hypotheses}

In this paper, our research context is digital music purchase intention. So we redefine each dimension of perceived value in Table 1.

\subsection{Main Effect}

3.1.1. Perceived Price. A negative correlation between perceived price and purchase intention has been proposed by many empirical studies. In the study of factors affecting consumer adoption of mobile banking, Luarn and Lin confirmed that the perceived economic costs will have a significant negative influence on user adoption [16]. Kuo and Yen confirmed the negative impact of perceived economic costs on purchase intention in its study of the factors influencing the use of $3 \mathrm{G}$ mobile value-added services by consumers [17]. Yingquan, in his study of paid online learning, also confirmed the negative correlation between perceived price and purchase intention.

In a study of why consumers are generally low on the purchase intention in digital music, Punj noted that the free ad-supported model gave most consumers a “ $\$ 0$ ” reference price, i.e., "free psychology." When digital music has a charge, a sense of loss was produced from a rational psychological point of view [18].

Based on the above analysis, this paper proposes the following hypothesis:

H1: perceived price has a negative impact on subhealthy people's digital music purchase intention.

3.1.2. Perceived Quality. Perceived quality is the most fundamental source of perceived value in practical value and is regarded as an antecedent variable of perceived value. Kim et al., in their study of consumer willingness to adopt mobile networks, proposed perceptual quality and perceived usefulness and such concepts. Perceived usefulness is an external manifestation of the perceived quality of product, and its research also confirms the positive impact of perceived quality on adoption [19].

In summary, product quality is consumer awareness and evaluation of product gains; in addition to products and services themselves, it is also based on the shopping environment and the experience process. For digital music, the perceptive quality measurement includes the objective quality of music content, richness and availability of music libraries, and consumer experience on music sites, and software shall also be included.

Based on the above analysis, this paper proposes the following hypothesis:

$\mathrm{H} 2$ : perceived quality has a positive effect on subhealthy people's digital music purchase intention. 
3.1.3. Social Value and Purchase Intention. Social value explores social impact from the individual to obtain social appreciation. Music is a personalized hedonic product, and its consumption is more reflected as a self-expression; in consideration of weak music copyright awareness and free enjoyment, paid music is a way of expressing individuality, status, and self-image in social situations [20], and in this way, consumers obtain social appreciation.

To sum up, this paper proposes the following hypothesis:

$\mathrm{H} 3$ : social value has a positive effect on subhealthy people's digital music purchase intention.

3.1.4. Emotional Value. Emotional value is derived from the pleasure, enjoyment, and interesting experience that consumers obtain from the product or the service. The impulsive consumption behavior by emotion dominating the purchase shows the influence of emotional value on the purchase intention [21].

Cai and Xu's researches confirmed that the aesthetic qualities and layout of the site design played an important role in enhancing the consumer's shopping experience, influencing consumer perception of shopping and perceived value in the shopping process [22]. Childers et al. [23], Chen et al. [24], Van der Heijden [25] and other scholars found that, in the Internet environment, the emotional value of the purchase will have a positive effect, especially in the enjoyment of the Internet for the purpose of product and service consumption; the emotional value of the purchasedriven role is more significant.

Digital music content service also happens to be a highly enjoyable product wherein consumers get the spirit of relaxation, pleasure, and emotional pursuit, rather than out of rational practical needs.

Based on the above analysis, this paper proposes the following hypothesis:

H4: emotional value has a positive effect on subhealthy people's digital music purchase intention.

\subsection{Moderating Effect}

3.2.1. Conditional Value. The positive influence of consumption context on individual behavior decision is defined by Sheth et al. as conditional value, which depends on the shopping environment and shopping conditions.

Pura (2005) divides perceived price dimensions into context-dependent and content-related categories, where conditional values are environment-dependent variables that describe the context in which consumers are buying and their current situation and state of mind. Sheth et al. in the definition of perceived value pointed out that under different circumstances of choice, the perceived value and its relationship with the purchase intention are different. For example, the Christmas tree as a symbol of Christmas, compared with weekdays, is of very high value in Christmas.

Therefore, decision-making environments influence the decision-making by interfering with or enhancing the context-dependent perceived value and the path of decision-making behavior. The influence of perceived value on purchase intention is dependent on the specific environ- ment. In analyzing the relationship between the consumption of digital music and the influence of perceived value and decision-making behavior on the decision-making path, it is necessary to consider the role of conditional value. For example, when consumers want to get a specific song and cannot find a free download path, due to the urgency of demand, its perception of price and risk will be relegated to the second place.

Since previous studies have shown that conditional value will not affect the perceived price and consumers' digital music purchase intention, as well as the perceived quality and consumers' digital music purchase intention, this time it is not included in this research.

Based on the above analysis, this paper proposes the following hypothesis:

$\mathrm{H} 5 \mathrm{a}$ : conditional value strengthens the negative relationship between the social value and subhealthy people's digital music purchase intention.

H5b: conditional value weakens the positive relationship between the emotional value and subhealthy people's digital music purchase intention.

3.2.2. Epistemic Value. Epistemic value refers to the value of novelty and satisfaction of trying new things and learning new ways of doing things. In the case of digital music consumption, epistemic value includes the curiosity of consumers for paid music services and satisfaction by testing the new paid services. The curiosity of new products, innovation, and the pursuit of diversity are the most important triggers of consumer purchase motivation [26].

Duman and Matilla's research shows that when consumers are seeking hedonic value, the pursuit of novelty is more motivating than purchasing behavior for the purpose of seeking practical value [27]. In the same period, the results of domestic scholars show that consumer innovation has a significant moderating effect on the negative impact of functional risk on a persistent information search.

Digital music is usually used as a kind of hedonic relaxation product, and it is in the stage of transition from new things to daily necessities in our country. Because the pursuit of novelty is a one-time process and does not have repetitive characteristics, this paper holds that epistemic value moderates the relationship between perceived price, perceived risk, and purchase intention through higher pursuit of novelty or new knowledge $[28,29]$.

Since previous studies have shown that epistemic value will not affect the perceived price and consumers' digital music purchase intention, as well as the perceived quality and consumers' digital music purchase intention, this time it is not included in this research.

Based on the above analysis, this paper makes the following hypothesis:

H6a: epistemic value strengthens the positive relationship between the social price and subhealthy people's digital music purchase intention.

H6b: epistemic value weakens the positive relationship between the emotional value and subhealthy people's digital music purchase intention. 
3.3. Research Models. Based on the above hypothesis, the research model is built and shown in Figure 1.

\section{Methodology}

Questionnaires were distributed online, and 346 questionnaires were retrieved, of which 92 were filled out. We finally got 254 valid respondents with a total valid recycling rate of $73.41 \%$.

\subsection{Reliability and Validity}

4.1.1. Reliability Analysis. We used Cronbach's $\alpha$ to analyze the reliability of each construct in the research model, and the results are shown in Table 2.

From Table 2, we can see that Cronbach's alpha of all our research constructs is greater than 0.7 ; these indicate that all our constructs have good reliability.

4.1.2. Validity Analysis. All measurement scales of our research constructs are based on extant top journal literature and have been cited several times, which always show good content validity.

We use AMOS to do confirmatory factor analysis to test construct validity, and the results are shown in Table 3. The results of first-order confirmatory factor analysis show that the default model is well fitting the data $\left(\chi^{2}=498.430\right.$, $\mathrm{DF}=209, \mathrm{CFI}=0.954$, TLI $=0.945$, and $\mathrm{RMSEA}=0.074$ ). In addition, all the factor loadings of the seven constructs were higher than 0.6 , all of the average variance extracted was greater than 0.5 , and all of composite reliability was greater than 0.7 ; these indicate that the main constructs of this study have good convergent validity. In order to test the discriminant validity, the correlation coefficient between independent variables should be less than the square root of the AVE value of two variables at the same time [28]. As can be seen from Table 4, the max correlation coefficient between these seven constructs is less than the square root of their average variance extracted. Therefore, all constructs in our research have good discriminant validity. In summary, all seven constructs in this study have good construct validity.

4.2. Empirical Model. The hypotheses involved in this study are tested by the following models. The variables in the model are expressed as follows: Purchase_intention is a dependent variable; Perceived_price, Perceived_quality, Social_value, and Emotional_value are independent variables; Conditional_value and Epistemic_value are independent variables; control variables include gender, age, education level, and income level; and $\varepsilon$ is a random disturbance term.

Model 1: Purchase_intention $=\beta_{10}+\beta_{11}$ Perceived $_{\text {- }}$ price $+\beta_{12}$ Perceived_quality $+\beta_{13}$ Social_value $+\beta_{14}$ Emotional value + control $+\varepsilon_{1}$.

Model 2: Purchase_intention $=\beta_{20}+\beta_{21}$ Perceived_price $+\beta_{22}$ Perceived_quality $+\beta_{23}$ Social_value $+\beta_{24}$ Emotional value $+\beta_{25}$ Conditional_value + control $+\varepsilon_{2}$.

Model 3: Purchase_intention $=\beta_{30}+\beta_{31}$ Perceived_price $+\beta_{32}$ Perceived_quality $+\beta_{33}$ Social_value $+\beta_{34}$ Emotional_ value $+\beta_{35}$ Conditional_value $+\beta_{36}$ Perceived_price $\times$

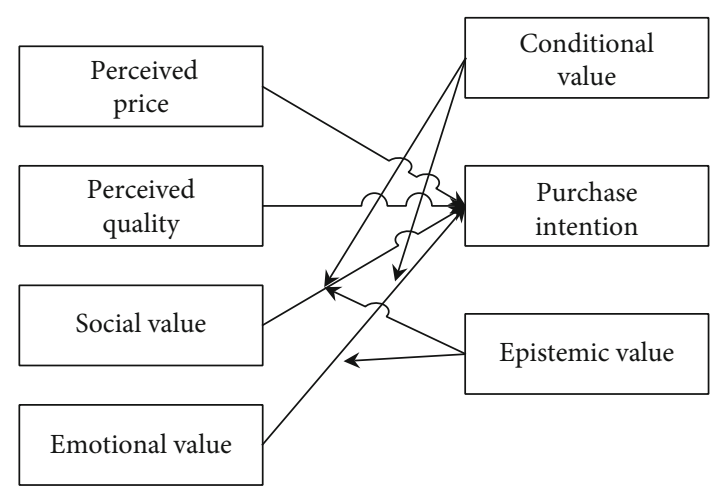

FIgURE 1: Conceptual model.

Conditional_value $+\beta_{37}$ Perceived_quality $\times$ Conditional_ value $+\beta_{38}$ Social_value $\times$ Conditional_value $+\beta_{39}$ Emotional _value $\times$ Conditional_value + control $+\varepsilon_{3}$.

Model 4: Purchase_intention $=\beta_{40}+\beta_{41}$ Perceived_price $+\beta_{42}$ Perceived_quality $+\beta_{43}$ Social_value $+\beta_{44}$ Emotional value $+\beta_{45}$ Epistemic_value + control $+\varepsilon_{4}$.

Model 5: Purchase_intention $=\beta_{50}+\beta_{51}$ Perceived_price $+\beta_{52}$ Perceived_quality $+\beta_{53}$ Social_value $+\beta_{54}$ Emotional value $+\beta_{55}$ Epistemic_value $+\beta_{56}$ Perceived_price $\times$ Epistemic _value $+\beta_{57}$ Perceived_quality $\times$ Epistemic_value $+\beta_{58}$ Social_ value $\times$ Epistemic_value $+\beta_{59}$ Emotional_value $\times$ Epistemic value + control $+\varepsilon_{5}$.

Among all the models listed above, model 1 is used to test hypotheses $\mathrm{H} 1, \mathrm{H} 2, \mathrm{H} 3$, and $\mathrm{H} 4$. Models 2 and 3 are used to test hypotheses $\mathrm{H} 5 \mathrm{a}, \mathrm{H} 5 \mathrm{~b}, \mathrm{H} 5 \mathrm{c}$, and H5d. Models 4 and 5 are used to test hypotheses H6a, H6b, H6c, and H6d.

4.3. Hypothesis Test. The regression results of models 1-5 are organized in Table 5.

4.3.1. Main Effect. In our study, hypothesis $\mathrm{H} 1$ suggests that perceived price has a positive impact on subhealthy people's digital music purchase intention. As we can see from the result of model 1 in Table 5, the regression coefficient of perceived price is $\beta_{11}=-0.052(p>0.10)$. Thus, $\mathrm{H} 1$ has not received support.

Hypothesis $\mathrm{H} 2$ supposes that perceived quality is positively related to subhealthy people's digital music purchase intention. In model 1 , the regression coefficient of perceived quality is $\beta_{12}=0.153(p<0.01)$. Therefore, $\mathrm{H} 2$ has received support.

Hypothesis $\mathrm{H} 3$ suggests that social value has a positive effect on subhealthy people's digital music purchase intention. In model 1 , the regression coefficient of perceived quality is $\beta_{13}=0.320(p<0.01)$. Therefore, H3 is supported in this study.

Hypothesis $\mathrm{H} 4$ supposes that emotional value is positively related to subhealthy people's digital music purchase intention. In model 1, the regression coefficient of perceived quality is $\beta_{14}=0.447(p<0.01)$. Therefore, $\mathrm{H} 4$ has received support.

4.3.2. Moderating Effect. In this paper, the two moderator variables are conditional value and epistemic value. Both of 
TABLE 2: Reliability analysis results.

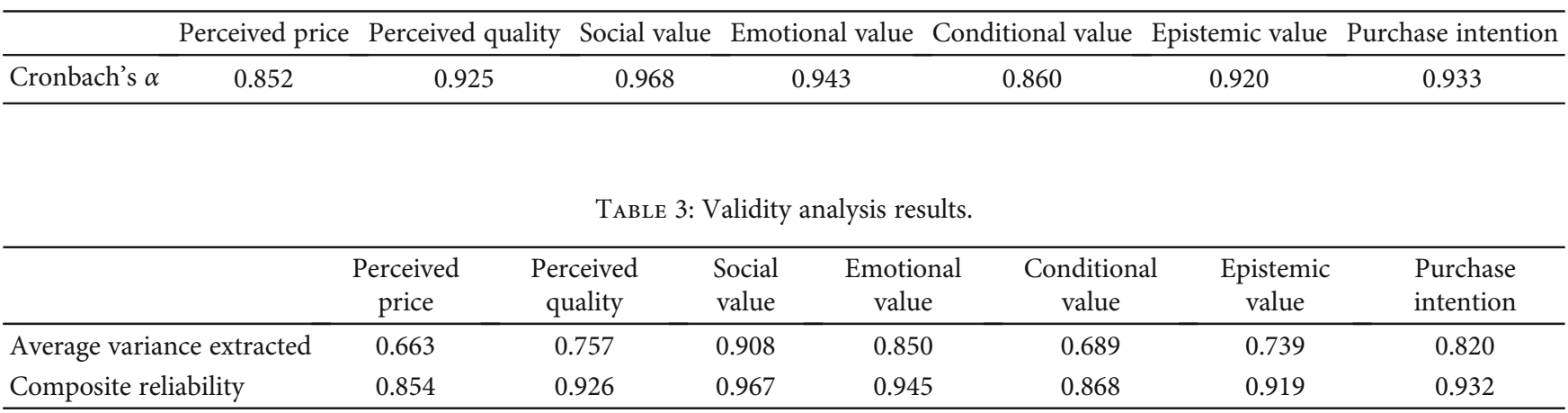

TABLE 4: Analysis of discriminant validity.

\begin{tabular}{lcccccc}
\hline Variable & 1 & 2 & 3 & 4 & 5 & 6 \\
\hline 1. Perceived price & 1 & & & & & \\
2. Perceived quality & -0.044 & 1 & & & & \\
3. Social value & -0.047 & 0.646 & 1 & 1 & 1 & \\
4. Emotional value & -0.113 & 0.697 & 0.916 & 0.852 & 0.802 & 0.849 \\
5. Conditional value & -0.056 & 0.751 & 0.736 & 0.907 & 0.821 \\
6. Epistemic value & -0.085 & 0.859 & 0.702 & 0.879 & & 1 \\
7. Purchase intention & -0.132 & & & & \\
\hline
\end{tabular}

TABLE 5: The results of linear regression analysis in this study.

\begin{tabular}{|c|c|c|c|c|c|}
\hline Model name & Model 1 & Model 2 & Model 3 & Model 4 & Model 5 \\
\hline Gender & $0.000(0.105)$ & $-0.004(0.100)$ & $0.030(0.101)$ & $-0.012(0.104)$ & $-0.018(0.104)$ \\
\hline Age & $-0.085(0.062)$ & $-0.074(0.059)$ & $-0.064(0.060)$ & $-0.111(0.063)$ & $-0.099(0.063)$ \\
\hline Education & $0.016(0.058)$ & $0.027(0.056)$ & $0.019(0.055)$ & $0.020(0.058)$ & $0.009(0.057)$ \\
\hline Income & $0.055(0.044)$ & $0.047(0.042)$ & $0.028(0.042)$ & $0.070(0.044)$ & $0.052(0.045)$ \\
\hline Perceived price & $-0.052(0.037)$ & $-0.065(0.036)$ & $-0.063(0.036)$ & $-0.050(0.037)$ & $-0.049(0.037)$ \\
\hline Perceived quality & $0.153^{* *}(0.041)$ & $0.059(0.043)$ & $0.043(0.043)$ & $0.087(0.050)$ & $0.108^{*}(0.051)$ \\
\hline Social value & $0.320^{* *}(0.061)$ & $0.336^{* *}(0.057)$ & $0.438^{* *}(0.066)$ & $0.301^{* *}(0.061)$ & $0.351^{* *}(0.063)$ \\
\hline Emotional value & $0.447^{* *}(0.066)$ & $0.300^{* *}(0.070)$ & $0.221^{* *}(0.074)$ & $0.402^{* *}(0.069)$ & $0.360^{* *}(0.069)$ \\
\hline Conditional value & & $0.272^{* *}(0.054)$ & $0.279^{* *}(0.055)$ & & \\
\hline Perceived price $\times$ conditional value & & & $-0.016(0.023)$ & & \\
\hline Perceived quality $\times$ conditional value & & & $0.017(0.026)$ & & \\
\hline Social value $\times$ conditional value & & & $-0.124^{* *}(0.041)$ & & \\
\hline Emotional value $\times$ conditional value & & & $0.108^{*}(0.046)$ & & \\
\hline Epistemic value & & & & $0.139^{*}(0.061)$ & $0.119(0.061)$ \\
\hline Perceived price $\times$ epistemic value & & & & & $-0.011(0.020)$ \\
\hline Perceived quality $\times$ epistemic value & & & & & $0.023(0.025)$ \\
\hline Social value $\times$ epistemic value & & & & & $-0.113^{* *}(0.037)$ \\
\hline Emotional value $\times$ epistemic value & & & & & $0.090^{*}(0.040)$ \\
\hline$N$ & 254 & 254 & 254 & 254 & 254 \\
\hline$F$ & $103.78^{* *}$ & $104.26^{* *}$ & $75.21^{* *}$ & $94.40^{* *}$ & $67.87^{* *}$ \\
\hline Adjusted $R^{2}$ & 0.765 & 0.784 & 0.773 & 0.769 & 0.775 \\
\hline
\end{tabular}

Note: standard error of the regression coefficient in parentheses. ${ }^{*} p<0.05,{ }^{* *} p<0.01$. 
them are continuous variables, so the cross-product direct interaction method is adopted to test the interaction of moderating variables.

(1) Moderating Effect of Conditional Value. Hypothesis H5a proposes that conditional value weakens the positive relationship between the social value and subhealthy people's digital music purchase intention. As we can see from model 3 in Table 5, the regression coefficient of the interaction term between the conditional value and social value is $\beta_{38}=-0.124(p<0.01)$. Thus, H5a has received support.

Hypothesis H5b suggests that conditional value strengths the positive relationship between the emotional value and subhealthy people's digital music purchase intention. In model 3 , the regression coefficient of the interaction term between the conditional value and emotional value is $\beta_{39}=$ $0.108(p<0.05)$. Therefore, H5b is supported in our study.

As we can see from Figure 2, when the conditional value is low, the relationship between the social value and subhealthy people's digital music purchase intention is positive, but when the conditional value is high, the relationship turns to be negative. Thus, the conditional value significantly weakens the relationship between the social value and subhealthy people's digital music purchase intention.

In Figure 3, when the conditional value is low, the relationship between the emotional value and subhealthy people's digital music purchase intention is positive but less; when the conditional value is high, the relationship turns to be more positive. Therefore, the conditional value significantly strengthens the relationship between the emotional value and subhealthy people's digital music purchase intention.

(2) Moderating Effect of Epistemic Value. Hypothesis H6a suggests that the epistemic value weakens the positive relationship between the social value and subhealthy people's digital music purchase intention. As we can see from model 5 in Table 5, the regression coefficient of the interaction term between the epistemic value and social value is $\beta_{58}=-0.113$ $(p<0.01)$. Therefore, H6a has received support.

Hypothesis H6b proposes that the epistemic value strengthens the positive relationship between the emotional value and subhealthy people's digital music purchase intention. In model 5, the regression coefficient of the interaction term between the epistemic value and emotional value is $\beta_{59}=0.090(p<0.05)$. Therefore, H5b is supported in this study.

As we can see from Figure 4, when the epistemic value is low, the relationship between the social value and subhealthy people's digital music purchase intention is positive, but when the epistemic value is high, such relationship turns to be negative. Thus, the epistemic value substantially weakens the relationship between the social value and subhealthy people's digital music purchase intention.

As shown in Figure 5, when the epistemic value is low, the relationship between the emotional value and subhealthy people's digital music purchase intention is positive but small; when the epistemic value is high, such positive relationship turns to be greater. Therefore, the epistemic value

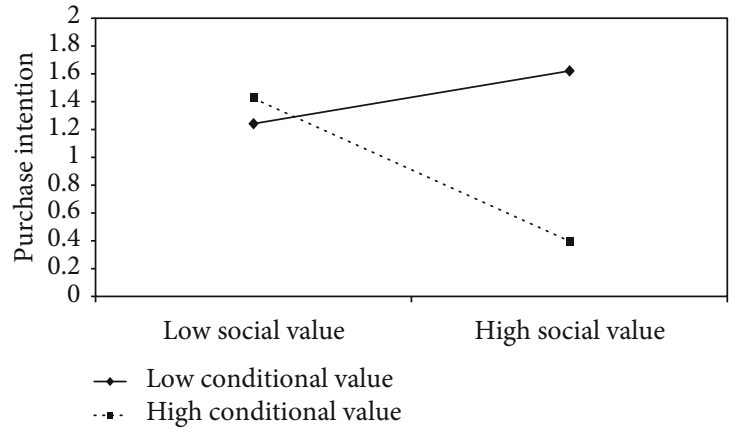

FIgURE 2: The interaction effect between the conditional value and social value.

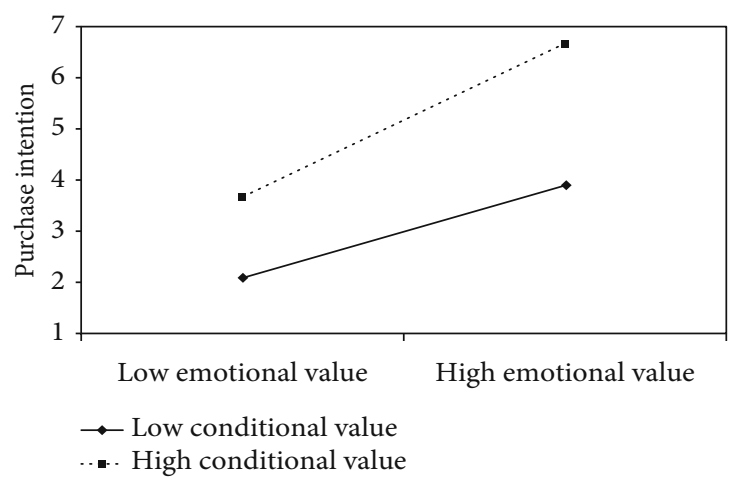

Figure 3: The interaction effect between the conditional value and emotional value.

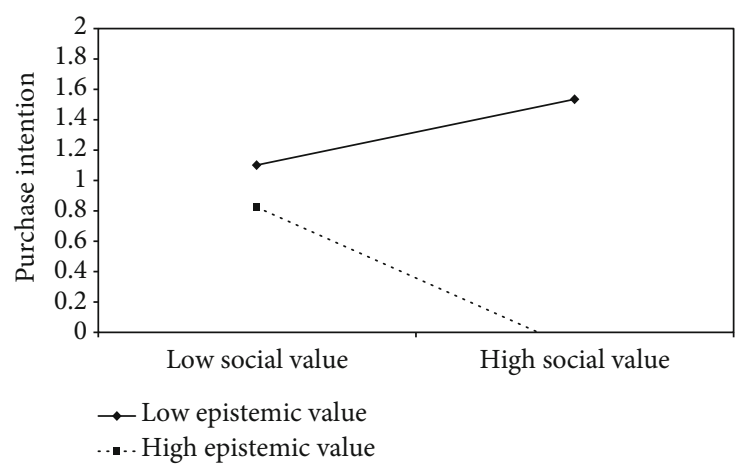

FIgURE 4: The interaction effect between the epistemic value and social value.

significantly strengthens the relationship between the emotional value and subhealthy people's digital music purchase intention.

In summary, the moderating effects proposed in hypotheses $\mathrm{H} 5 \mathrm{a}, \mathrm{H} 5 \mathrm{~b}, \mathrm{H} 6 \mathrm{a}$, and $\mathrm{H} 6 \mathrm{~b}$ all received support in our study. Specifically, both the conditional value and epistemic value moderate the relationship between the social value and subhealthy people's digital music purchase intention and the relationship between the emotional value and subhealthy people's digital music purchase intention. 


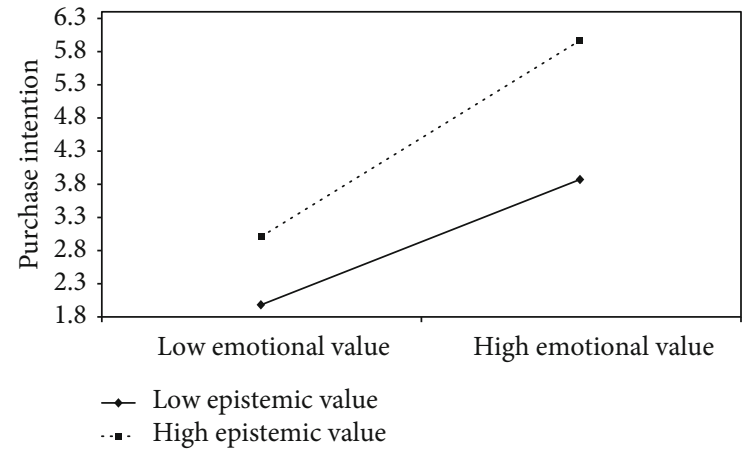

Figure 5: The interaction effect between the epistemic value and emotional value.

\section{Discussion}

\subsection{Analysis Conclusion}

(1) The effect of emotional value on purchase intention is the strongest among the perceived value dimensions. This result is consistent with the hedonic nature of mobile digital music; perceived quality has a significant positive effect on purchase intention, music quality, music library resources, mobile terminal design, and functional design, and other factors affect the user purchase intention. The quality of purchase intention also plays a significant positive effect. This conclusion is consistent with the made existing researches. Quality of digital music, music library resources, and interactive design of the mobile terminal and functional design are important factors affecting the subhealthy people's purchase intention

(2) Compared with the above significant conclusion, the effect of perceived price and purchase intention is not significant. The results are different from those of most scholars before, and the reason may be as follows: first, the reason that subhealthy people are reluctant to buy music is not caused by the absolute high price but based on the psychology of resisting pay for free product, or free music has met the demand; second, consumers believe that the price of mobile digital music is affordable compared to that of digital music; and third, paid mobile digital music is a virtual product of lower price, which does not help much for the promotion of social prestige and status, and no buying of mobile digital music can lead to ridicule. Revelation to the mobile terminal vendor is to improve consumer purchase intention which shall focus not only on lower prices but also more on improving quality strategies to enhance the user experience

(3) Social value has a significant impact on purchase intention. This article believes that the possible reasons are as follows: first, paid mobile digital music can show respect for others' labor, which is helpful to enhance social prestige and status and secondly, at present, Chinese people are concerned about digital music The gradual improvement of copyright knowledge does not mean that relevant laws are becoming more and more perfect. This behavior can be recognized by others

(4) Conditional value and epistemic value both have a negative moderating effect on the relationship between the social value and purchase intention. When subhealthy people perceive that paid music only produces a temporary sense of comfort in the context of its time and space, this value perception is not conducive to the formation of purchase intentions. If mobile terminal vendors can enable mobile digital music to bring more fresh experiences to subhealthy people and bring new knowledge or learning value, subhealthy people will be less sensitive to perceived loss. Mobile terminal vendors should create conditional value and increase the urgency of paid music, such as regularly launching prerelease versions of therapeutic music to increase the curiosity and entertainment of paid music services

(5) Conditional value and epistemic value have a positive moderating effect on the relationship between the emotional value and purchase intention. Subhealthy people can increase their satisfaction from music under the appropriate time and space background, which is conducive to the formation of purchase intention. If the mobile terminal vendor considers improving the details of the feelings of the subhealthy people when designing a personalized solution, this will help promote the purchase intention of the subhealthy people

5.2. Managerial Implication. Emotional value, social value, and perceived quality have a significant impact on purchase intention, and the mobile terminal vendor should be able to create emotional pleasure and good experience for subhealthy people.

(1) The mobile terminal vendor shall have unique attitude and feelings by clearing their own position, finding a strategy to improve the user experience to win reputation, and allowing users to feel a sense of belongingness, and in this way, they will willingly pay. The user interface shall be concise, clear, and easy to use, enhance the visual and layout logic, in line with the fragmentation characteristics of music products in modern times, and create use atmosphere. The use of comments is to enhance the user's emotional and adherence to content to improve listening experience; music library diversity and quality shall be enhanced by long-term cooperative relationship with record companies or musicians

(2) The perceived price is not a significant factor for the purchase intention; that is, consumers believe that the current pricing for digital music is not high, so the price reduction is not a good way to improve 
purchase intention. However, the differentiation pricing strategy shows characteristics, such as an attempt to open up a pricing strategy and differential pricing; a combination of multiple payment models can improve user retention and loyalty and help attract potential customers

5.3. Limitations and Future Research. However, due to the objective conditions, there are some limitations and shortcomings in the study.

First of all, the geographical distribution of the questionnaire is relatively concentrated, and the respondents' academic record is higher than the overall sample, ignoring the possible impact of regional differences for an individual perceived value.

Secondly, most of the respondents in this study are subhealthy people who have already had mobile digital music purchase experience and cannot distinguish between prepurchase perception and postpurchase perception.

In the end, this paper does not explore the dimensions of antecedent variable of the perceived value. It only studies the influence of perceived quality on purchase intention and lack of variables which impact perceived quality, such as characteristics of the mobile terminal, smoothness of use, cross-platform service capability, and perceived ease of use. Therefore, the model is limited in practical application.

\section{Data Availability}

The data used to support the findings of this study are available from the corresponding author upon request.

\section{Conflicts of Interest}

The authors declare that they have no conflicts of interest.

\section{Acknowledgments}

This article was supported by the Fujian Provincial Social Science Planning Project in 2020: Research on Capacity Building of Regional Medical Collaborative Innovation Community under the Background of "Internet + Medical" (No. FJ2020B038). The authors wish to thank Professor Peng LF and Ms. Wang Huan for their helpful comments on earlier drafts.

\section{References}

[1] D. Souza and R. Baldanza, "The e-consumer in light of the perceived value theory: a study on the acceptance of mobile commerce," BASE-Revista de Administração e Contabilidade da Unisinos, vol. 15, no. 3, pp. 238-253, 2018.

[2] K.-Y. Lin, Y.-T. Wang, and T. K. Huang, "Exploring the antecedents of mobile payment service usage," Online Information Review, vol. 44, no. 1, pp. 299-318, 2020.

[3] M. H. Kim, L. M. Marulis, J. K. Grammer, F. J. Morrison, and W. J. Gehring, "Motivational processes from expectancy-value theory are associated with variability in the error positivity in young children," Journal of Experimental Child Psychology, vol. 155 , pp. 32-47, 2017.
[4] N. Shaw and K. Sergueeva, "The non-monetary benefits of mobile commerce: extending UTAUT2 with perceived value," International Journal of Information Management, vol. 45, pp. 44-55, 2018.

[5] Z. Zhang and H. Q. Wang, "How online social ties and product-related factors influence purchasing intention in mobile social commerce context," International Journal of Mobile Communications, vol. 17, no. 2, pp. 191-215, 2019.

[6] S. W. Joe, Y. H. Tsai, C. P. Lin, H. C. Ma, and C. K. Chiu, "Assessing perceived value: moderating effects of susceptibility to brand prestige and susceptibility to normative influence," Review of Managerial Science, vol. 11, no. 3, pp. 717-735, 2017.

[7] M. Choi, R. Law, and C. Y. Heo, "An investigation of the perceived value of shopping tourism," Journal of Travel Research, vol. 57, no. 7, pp. 962-980, 2018.

[8] O. S. Itani, A.-N. Kassar, and S. M. C. Loureiro, "Value get, value give: the relationships among perceived value, relationship quality, customer engagement, and value consciousness," International Journal of Hospitality Management, vol. 80, pp. 78-90, 2019.

[9] C. Lauckner, "The perceived value of online cancer resources among loved ones of people with cancer," Oncology Nursing Forum, vol. 45, no. 3, pp. 354-358, 2018.

[10] L. Aguiar, "Let the music play? Free streaming and its effects on digital music consumption," Information Economics \& Policy, vol. 41, pp. 1-14, 2017.

[11] N. Xi, "Research on the design method of wireless music channel access network based on mobile Internet," Revista De La Facultad De Ingenieria, vol. 32, no. 3, pp. 740-748, 2017.

[12] F. J. F. Coelho, C. M. Bairrada, and A. F. M. Coelho, "Functional brand qualities and perceived value: the mediating role of brand experience and brand personality[J]," Psychology Marketing, vol. 4, pp. 41-55, 2020.

[13] X. Hu, "Evaluating mobile music services in China: an exploration in user experience," Journal of Information Science, vol. 45, no. 1, pp. 16-28, 2019.

[14] T. J. Gerpott and P. Meinert, "Not just every user of mobile music streaming shares the same characteristics: a classification analysis of mobile network operator subscribers in Germany," Telematics Informatics, vol. 41, pp. 19-33, 2019.

[15] S. McGrath and S. Love, "The user experience of mobile music making: an ethnographic exploration of music production and performance in practice," Computers in Human Behavior, vol. 72, pp. 233-245, 2017.

[16] M. Pura, "Linking perceived value and loyalty in locationbased mobile services," Managing Service Quality, vol. 15, no. 15, pp. 509-538, 1991.

[17] Y. F. Kuo and S. N. Yen, "Towards an understanding of the behavioral intention to use $3 \mathrm{G}$ mobile value-added services," Computers in Human Behavior, vol. 25, no. 1, pp. 103-110, 2009.

[18] G. Punj, “The relationship between consumer characteristics and willingness to pay for general online content: implications for content providers considering subscription-based business models," Marketing Letters, vol. 26, no. 2, pp. 175-186, 2015.

[19] H. W. Kim, H. C. Chan, and S. Gupta, "Value-based adoption of mobile Internet: an empirical investigation," Decision Support Systems, vol. 43, no. 1, pp. 111-126, 2007.

[20] L. Leung and R. Wei, "More than just talk on the move: uses and gratifications of the cellular phone," Journalism \& Mass Communication Quarterly, vol. 77, no. 2, pp. 308-320, 2000. 
[21] M. P. Gardner, "Mood states and consumer behavior: a critical review," Journal of Consumer Research, vol. 12, no. 3, pp. 281300, 1985.

[22] S. Cai and Y. Xu, "Designing not just for pleasure: effects of web site aesthetics on consumer shopping value," International Journal of Electronic Commerce, vol. 15, no. 4, pp. 159-188, 2014.

[23] T. L. Childers, C. L. Carr, J. Peck, and S. Carson, "Hedonic and utilitarian motivations for online retail shopping behavior," Journal of Retailing, vol. 77, no. 4, pp. 511-535, 2001.

[24] C.-H. Chen, F.-J. Hwang, and H.-Y. Kung, "Travel time prediction system based on data clustering for waste collection vehicles," IEICE Transactions on Information and Systems, vol. E102.D, no. 7, pp. 1374-1383, 2019.

[25] H. Van der Heijden, "User acceptance of hedonic information systems,” MIS Quarterly, vol. 28, no. 4, pp. 695-704, 2004.

[26] E. C. Hirschman, "Innovativeness, novelty seeking, and consumer creativity," Journal of Consumer Research, vol. 7, no. 3, pp. 283-295, 1980.

[27] T. Duman and A. S. Mattila, "The role of affective factors on perceived cruise vacation value," Tourism Management, vol. 26, no. 3, pp. 311-323, 2005.

[28] S. Onkar, "Digital rids a music academy from manual pain," Dataquest, vol. 35, no. 1, pp. 72-74, 2017.

[29] W. Dai and K. Yu, "Contestability in the digital music player market," Journal of Industry Competition Trade, vol. 19, no. 2, pp. 293-311, 2019. 